\title{
PERAN FLEKSIBILITAS STRATEG DAN ORIENTASI PASAR PADA PENINGKATAN INOVASI DAN KINERJA USAHA KECIL MENENGAH SEKTOR INDUSTRI PENGOLAHAN KOTA MALANG
}

\author{
Sumiati \\ Department of Management, Faculty of Economoy and Business, Universitas Brawijaya \\ E-mail:sumiati@ub.ac.id
}

\begin{abstract}
ABSTRAK
Industri pengolahan merupakan industri yang sedang berkembang dan menyumbangkan sekitar $1 / 5$ dari total Produk Domestik Bruto Indonesia. Penelitian ini menganalisis faktor-faktor yang mempengaruhi kinerja UKM sektor industri pengolahan di Kota Malang. Beberapa variabel seperti lingkungan internal dan ekternal, orientasi pasar, di anggap sebagai variabel penting yang mempengaruhi kinerja UKM, penelitian ini bertujuan menguji pengaruh orientasi pasar dan fleksibilitas strategi terhadap inovasi dan kinerja UKM. Penelitian ini merupakan penelitian eksplanatori yang menggunakan sampel sebanyak 180 manajer UKM industri pengolahan di Kota Malang. Data yang dikumpulkan dianalisis dengan menggunakan Structural Equation Modelling (SEM). Fleksibilitas strategi dan orientasi pasar ditemukan secara langsung (direct effect) mempengaruhi inovasi dan kinerja perusahaan secara positif. Selain itu, inovasi teruji berperan sebagai mediator dalam pengaruh fleksibilitas strategi maupun orientasi pasar terhadap kinerja perusahaan. Begitu pula dengan kinerja perusahaan teruji berperan sebagai mediator bagi masing-masing fleksibilitas strategi maupun orientasi pasar terhadap inovasi.
\end{abstract}

Kata Kunci: fleksibilitas strategi, orientasi pasar, inovasi, kinerja UMKM

\begin{abstract}
The processing industry is a growing industry and accounts for around $1 / 5$ of Indonesia's total Gross Domestic Product. This study analyzes the factors that influence the performance of SMEs in the manufacturing industry sector in Malang. Some variables such as internal and external environment, market orientation, are considered as important variables that influence the performance of SMEs, this study aims to examine the effect of market orientation and strategy flexibility on SME innovation and performance. This research is an explanatory study using a sample of 180 managers of processing industry SMEs in Malang. The data collected was analyzed using Structural Equation Modeling (SEM). Strategic flexibility and market orientation are found directly (direct effect) to affect innovation and company performance positively. In addition, proven innovation acts as a mediator in the influence of strategy flexibility and market orientation on company performance. Likewise, company performance has a role as a mediator for each strategy flexibility and market orientation towards innovation.
\end{abstract}

Keywords: Strategy flexibility, market orientation, innovation, MSME performance 


\section{Sumiati}

\section{PENDAHULUAN}

Industri pengolahan saat ini semakin mendapat perhatian khusus dari pemerintah seiring semakin besarnya kontribusi dari unit usaha pada sektor ini terhadap pendapatan nasional dan daerah. Unit usaha sektor industri pengolahan dianggap mampu untuk menciptakan lapangan kerja sehingga selain meningkatkan Produk Domestik Regional Bruto (PDRB) unit usaha dari sektor industri secara tidak langsung juga mampu meningkatkan kesejahteraan masyarakat daerah.

Kota Malang merupakan salah satu daerah dimana unit usaha dari sektor industri berkembang dengan sangat baik. Pada tahun 2016 jumlah unit usaha dari seluruh subsektor industri hanya sebesar 141 unit, sementara di tahun 2017 jumlah unit usaha di sektor industri meningkat pesat menjadi 2.611 unit usaha. Peningkatan jumlah unit usaha diikuti dengan peningkatan jumlah PDRB yang dihasilkan dari sektor lapangan usaha industri. Pada tahun 2016 nilai kontribusi sektor lapangan usaha industri pengolahan adalah sebesar Rp 14.521,8 Milyar, nilai tersebut mengalami peningkatan di tahun 2017 menjadi Rp 15.663,8 Milyar. Penyerapan tenaga kerja dari lapangan usaha industri pengolahan juga mengalami peningkatan di tahun 2017 menjadi 70.091 angkatan kerja, dimana pada tahun 2015 jumlah angkatan kerja yang terserap pada lapangan usaha ini sebesar 53.922 angkatan kerja data dari Badan Pusat B. P. R. I. J. Statistik (2017).

Peningkatan signifikan dari sector industry pengolahan diindikasi karena beberapa alasan, salah satunya adalah lingkungan internal dan eksternal perusahaan. Faktor lingkungan eksternal yang diindikasi berperan penting dalam peningkatan jumlah unit usaha di subsektor ini adalah tingginya permintaan pasar terhadap produk industry pengolahan, misalnya makanan dan minuman. Faktor eksternal lain yang mendukung peningkatan jumlah unit usaha di subsektor ini adalah kemudahan akses bahan baku serta dukungan dari pemerintah daerah kepada calon wirausaha baru dalam membuka usaha.

Walaupun kontribusi industry pengolahan terhadap PDRB dapat dikatakan cukup tinggi, namun secara umum, menurut data Badan Pusat B. P. Statistik, Republik Indonesia Jakarta (2018) terjadi penurunan kontribusi industry pengolahan terhadap PDRB dari 28,92\% di tahun 2016, menjadi 25,19\% di tahun 2017. Kondisi penurunan kontribusi tersebut menunjukkan perlu adanya pemerataan pertumbuhan jumlah unit usaha di subsektor industri lain, tujuannya adalah untuk menjaga stabilitas kontribusi terhadap PDRB sekaligus menjaga persaingan positif antar unit usaha yang beroperasi di Kota Malang. Pada penelitian tahun pertama telah ditunjukkan bahwa perubahan lingkungan internal dan eksternal dapat mempengaruhi orientasi pasar perusahaan. Perubahan ini terkait dengan bagaimana perencanaan dan fleksibilitas strategi dari perubahan tersebut. 


\section{Jurnal Manajemen Teori dan Terapan \\ Tahun 12. No. 3, Desember 2019}

Unit usaha yang tidak dapat menganalisis lingkungan internal dan eksternal yang ada di sekitarnya diduga tidak dapat menentukan orientasi pasar, yang kemudian membuat pelaku usaha tidak berani untuk bersaing di pasar yang tidak dapat diprediksi. Di Kota Malang, rendahnya perkembangan unit usaha di subsektor selain industri makanan dan minuman diduga karena sebagian besar pelaku usaha tidak memiliki fleksibilitas strategi. Pada penelitian tahun kedua, peneliti ingin mengetahui apakah unit usaha yang memiliki fleksibilitas strategi dan orientasi pasar memiliki kinerja yang lebih baik dibandingkan dengan unit usaha lain. Kinerja yang lebih unggul dari unit usaha dengan fleksibilitas strategi dan orientasi pasar diduga karena unit usaha tersebut mampu menghasilkan inovasi yang kemudian mempengaruhi peningkatan kinerja unit usaha secara keseluruhan.

Walaupun konstruk orientasi pasar telah banyak diteliti dan telah terbukti pengaruhnya terhadap kinerja perusahaan (Al Idrus et al., 2019; Gruber-Muecke dan Hofer, 2015; Mele dan Russo-Spena, 2015), namun penelitian yang menjelaskan proses terjadinya pengaruh tersebut masih belum dilakukan. Oleh karena itu, perlu adnya penelitian lebih lanjut yang menganalisis pengaruh orientasi pasar terhadap kinerja perusahaan dengan menambahkan variabel lain seperti innovasi dan fleksibilitas strategi sehingga kekuatan prediksi dari model yang dibentuk dapat dijelaskan secara lebih tepat. Lebih lanjut, penelitian mengenai fleksibilitas strategi pada usaha kecil dan menengah di Indonesia masih belum banyak dilakuakn, terutama pada sector industry pengolahan, sehingga penelitian ini perlu untuk dilakukan.

Penelitian ini bertujuan untuk menganalisis pengaruh fleksibilitas strategi, orientasi pasar dan inovasi terhadap kinerja unit usaha sektor pengolahan di Kota Malang. Penelitian ini diharapkan akan memberikan kontribusi kepada khasanah ilmu pengetahuan mengenai variabel-variabel yang mempengaruhi kinerja UMKM industri pengolahan, dan model yang dibangun diharapkan bisa menjadi acuan bagi para praktisi UMKM industry pengolahan untuk diterapkan dalam upaya peningkatan kinerja perusahaan. Lebih lanjut, penelitian ini diharapkan dapat memberikan kontribusi praktis bagi para pengusaha kecil pada industry pengolahan yang ingin meningkatkan kinerjanya, sehingga para pengusaha dapat mengalokasikan sumberdaya yang dimiliki secara tepat.

\section{LANDASAN TEORI}

\section{Fleksibilitas Strategi}

Fleksibilitas strategi merupakan suatu kemampuan yang dimiliki perusahaan dalam menanggapi perubahan-perubahan yang terjadi pada pasar. Brozovic (2018) menjelaskan fleksibilitas strategis sebagai kemampuan perusahaan untuk merespon ketidakpastian dengan melakukan penyesuaian terhadap target yang telah ditetapkan oleh perusahaan 


\section{Sumiati}

berdasarkan kemampuan dan sumber daya yang tersedia oleh perusahaan. Pemaparan tersebut menjelaskan bahwa perusahaan yang memiliki fleksibilitas strategis cenderung lebih dinamis dalam menentukan keputusan dan perencanaan strategis. Sifat dinamis yang dimiliki oleh perusahaan dengan fleksibilitas strategis kemudian tidak menjadikan perusahaan tersebut selalu merespon perubahan-perubahan yang terjadi di lingkungan eksternal, khususnya pasar. Perusahaan dengan fleksibilitas strategis yang baik melakukan beberapa pendekatan sebelum akhirnya memutuskan untuk melakukan penyesuaian terhadap perubahan lingkungan eksternal tersebut atau tidak.

Salah satu pendekatan yang dilakukan oleh perusahaan sebelum melakukan penyesuaian terhadap perubahan adalah analisis lingkungan internal dan eksternal. Penyesuaian hanya dilakukan perusahaan apabila perusahaan memiliki sumber daya internal yang cukup untuk menanggapi perubahan yang terjadi di lingkungan eksternal. Keputusan apakah penyesuaian perlu dilakukan atau tidak juga didasarkan pada penilaian apakah penyesuaian tersebut dapat membantu perusahaan meningkatkan kinerja perusahaan dan membangun keunggulan kompetitif di pasar menurut (Chan et al., (2017). Berdasarkan pemaparan tersebut dapat disimpulkan bahwa fleksibilitas strategis memerlukan pertimbangan yang matang dan tidak merubah perencanaan dasar yang telah diformulasikan pada perencanaan strategis sebelumnya.

Perusahaan yang memiliki fleksibilitas strategi cenderung memiliki potensi untuk melakukan inovasi dalam rangka menghadapi perubahan lingkungan eksternal. Grewal dan Tansuhaj (2001), memaparkan bahwa fleksibilitas strategis dilakukan perusahaan untuk meningkatkan kinerja sekaligus membangun keunggulan kompetitif di pasar, dengan demikian fleksibilitas strategis diduga memiliki pengaruh terhadap kinerja perusahaan. Maka Hipotesis penelitian ini diformulasikan:

H1: Fleksibilitas Strategi berpengaruh secara positif dan signifikan terhadap kinerja perusahaan

H3: Fleksibilitas Strategi berpengaruh secara positif dan signifikan terhadap inovasi

\section{Orientasi Pasar}

Ozkaya et al. (2015), memaparkan orientasi pasar merupakan serangkaian perilaku yang dilakukan oleh perusahaan dalam rangka mengumpulkan informasi tentang kebutuhan konsumen dan faktor-faktor yang membentuk kebutuhan tersebut. Informasi yang telah dikumpulkan, selanjutnya dapat digunakan oleh perusahaan untuk menentukan keputusankeputusan strategis dalam rangka meningkatkan kinerja perusahaan. Motif dasar perusahaan dalam melakukan orientasi pasar adalah adanya kesadaran bahwa lingkungan eksternal, khususnya konsumen memiliki sifat dinamis yang selalu berubah-ubah. 


\section{Jurnal Manajemen Teori dan Terapan \\ Tahun 12. No. 3, Desember 2019}

Konsumen merupakan pembentuk permintaan pasar, sehingga informasi tentang kebutuhan konsumen dapat menjadi dasar perusahaan dalam menciptakan sebuah nilai produk yang memiliki keunggulan kompetitif.

Aziz dan Samad (2016) dan Gruber-Muecke and Hofer (2015) menjelaskan tujuan perusahaan yang melakukan orientasi pasar adalah untuk meningkatkan kinerja perusahaan khususnya dari sisi pemasaran. Menurut Migdadi et al. (2017) melalui orientasi pasar, perusahaan dapat menganalisis perubahan kebutuhan konsumen dan kemudian menciptakan produk dengan nilai manfaat yang sesuai dengan kebutuhan tersebut Penilaian peningkatan kinerja perusahaan yang melakukan orientasi pasar dapat diukur melalui peningkatan jumlah penjualan, keuntungan, karyawan dan pangsa pasar (Migdadi et al., 2017; Ozkaya et al., 2015). Maka hipoteis penelitian diformulasikan:

$\mathrm{H} 2$ : Orientasi pasar berpengaruh positif dan signifikan terhadap kinerja perusahaan

$\mathrm{H} 4$ : Orientasi pasar berpengaruh positif dan signifikan terhadap inovasi

\section{Inovasi (Pasar, Produk, Proses)}

Kondisi pasar dan persaingan bisnis yang semakin tidak menentu dan terus berubah menuntut adanya inovasi guna meraih keunggulan bersaing. Aziz dan Samad (2016) menyatakan bahwa kunci sukses dari keunggulan bersaing adalah inovasi. Inovasi dapat dibedakan menjadi inovasi produk (Higgins, 1995; Nenonen et al., 2017; Zhang dan Duan, 2010), inovasi proses (Murat Ar dan Baki, 2011) dan inovasi pasar (Nenonen et al., 2017).

Hogan dan Coote (2014) mendefinisikan inovasi sebagai salah satu fungsi yang dimiliki perusahaan dalam melakukan perubahan untuk menciptakan suatu dimensi kinerja yang baru. Inovasi dapat dipicu oleh perubahan lingkungan internal dan eksternal perusahaan yang kemudian memberi kesempatan bagi perusahaan tersebut untuk menciptakan suatu tata cara atau sistematika proses yang baru dengan tujuan meningkatkan kinerja perusahaan secara keseluruhan. Berdasarkan pemaparan tersebut, inovasi dapat disimpulkan sebagai sebuah hasil yang dapat berupa strategi, tata cara, sistematika proses, atau perencanaan oleh perusahaan yang dilakukan sebagai tanggapan atas perubahan lingkungan internal dan eksternal (Drucker, 2014). Lebih lanjut, inovasi dilakukan apabila terdapat dua komponen yaitu perusahaan dan lingkungan di sekitarnya, dengan demikian inovasi tidak dapat diciptakan atau terbentuk apabila satu dari kedua komponen tersebut tidak terpenuhi. Perusahaan sebagai subjek yang akan menciptakan inovasi perlu mengetahui informasi perubahan lingkungan khususnya lingkungan eksternal. Perusahaan yang melakukan orientasi pasar pada umumnya memiliki informasi terkait perubahan kebutuhan lingkungan eksternal khususnya perubahan kebutuhan konsumen, dengan demikian perusahaan yang melakukan orientasi pasar memenuhi kedua komponen yang 


\section{Sumiati}

diperlukan untuk penciptaan inovasi. Berdasarkan pemaparan tersebut maka dapat diduga bahwa inovasi dapat ditemukan pada perusahaan-perusahaan yang melakukan orientasi pasar.

Tanggap terhadap perubahan dan melakukan penyesuaian strategis terhadap perubahan tersebut merupakan salah satu ciri dari perusahaan yang memiliki fleksibilitas stra tegis. Fleksibilitas strategis yang dilakukan perusahaan bertujuan untuk membangun keunggulan kompetitif di pasar dengan memanfaatkan sumber daya yang tersedia dalam menghadapi perubahan lingkungan eksternal. Berdasarkan motif dan tujuan dari penyesuaian strategis yang dilakukan perusahaan, dapat diduga inovasi juga dapat ditemukan pada perusahaan-perusahaan yang memiliki fleksibilitas strategis.

Salah satu tujuan utama dari penciptaan inovasi oleh perusahaan adalah untuk meningkatkan kinerja perusahaan secara keseluruhan (Doluca et al., 2018). Pengukuran kinerja perusahaan secara keseluruhan dapat diukur melalui pengukuran kinerja perusahaan melalui pengamatan pada peningkatan jumlah penjualan, keuntungan, karyawan, dan pangsa pasar yang dimiliki oleh perusahaan (Gomes dan Wojahn, 2017). Maka hipotesis penelitian diformulasikan:

H5 : Inovasi berpengaruh positif dan signifikan terhadap kinerja perusahaan

\section{Kinerja Perusahaan}

Kinerja merupakan sebuah hasil yang ditunjukkan melalui perbandingan antara target dan capaian suatu unit kinerja dalam jangka waktu tertentu. Kinerja usaha kemudian didefinisikan sebagai pengukuran hasil yang dicapai oleh satu unit usaha dengan cara membandingkan target dan capaian hasil yang diperoleh unit usaha tersebut dalam suatu jangka waktu tertentu. Semrau et al. (2016) menjelaskan pengukuran kinerja suatu perusahaan dapat diukur melalui dua dimensi yaitu dimensi finansial dan dimensi nonfinansial. Pengukuran finansial dapat dilakukan melalui perbandingan perubahan nilai pada laporan keuangan yang diterbitkan oleh perusahaan. Pengukuran non-finansial diukur melalui kepuasan pemangku kepentingan dan pertumbuhan struktur organisasi.

Pengukuran kinerja perusahaan bersifat subjektif, artinya pengukuran kinerja sangat bergantung kepada subjek yang melakukan dan alat pengukuran yang digunakan. Fairoz et al. (2010) membentuk pengukuran kinerja dengan menggabungkan komponen finansial dan non-finansial. Komponen finansial meliputi pertumbuhan laba, sementara untuk komponen non- finansial diukur melalui pertumbuhan penjualan, karyawan, pangsa pasar, dan kepuasan pemilik usaha. Maka hipotesis mengenai pengaruh tidak langsung pada penelitian ini diformulasikan: 


\section{Jurnal Manajemen Teori dan Terapan \\ Tahun 12. No. 3, Desember 2019}

H6: Inovasi memediasi pengaruh fleksibilitas strategi terhadap kinerja perusahaan

H7: Inovasi memediasi pengaruh orientasi pasar terhadap kinerja perusahaan

\section{METODE}

Berdasarkan latar belakang, rumusan masalah, dan tujuan penelitian, penelitian ini merupakan jenis penelitian explanatory. Penelitian explanatory digunakan untuk mengetahui hubungan antara dua variabel atau lebih, dimana dalam penelitian ini pengaruh antar variabel yang akan diuji adalah strategic flexibility, orientasi pasar, inovasi, dan kinerja perusahaan.

Populasi pada penelitian ini adalah seluruh Usaha Kecil dan Menengah (UKM) di sektor lapangan usaha industry pengolahan yang beroperasi di Kota Malang. Sampel minimal menurut Roscoe agar dapat menghasilkan data relevan untuk penelitian ini adalah 40 pengelola atau manajer Usaha Kecil dan Menengah (UKM) di Kota Malang pada lapangan usaha industri pengolahan. Penentuan ini didasarkan pada jumlah variable pada penelitian ini (strategic flexibility, orientasi pasar, inovasi, dan kinerja perusahaan) dikalikan dengan 10. Namun, untuk mendapatkan hasil yang tidak bias, maka penelitian ini mengambil 180 sampel. Selanjutnya untuk memastikan bahwa pengumpulan data pada sampel benarbenar mewakilkan populasi, maka terdapat criteria yang perlu dipenuhi oleh sampel dengan menggunakan teknik purposive sampling. Kriteria yang harus dipenuhi oleh sampel penelitian ini adalah sebagai berikut:

1. Unit usaha yang dikelola termasuk ke dalam skala kecil atau menengah;

2. Berdomisili di Kota Malang, JawaTimur, Indonesia;

3. Unit usaha beroperasi pada lapangan usaha sektor industry pengolahan; dan

4. Dalam 5 tahun terakhir beroperasi sekurang-kurangnya 3 tahun berturut-turut. Data yang digunakan pada penelitian ini mencakup data primer dan data sekunder. Data primer didaptkan dari suvery langsung terhadap minimal 180 responden. Survey dilakukan dengan instrument kuesioner tertutup. Adapun data seknder akan diperoleh dari pihakpihak terkait seperti halnya dinas perindustrian, bapeda Kota Malang dan BPS.

Kajian dilakukan terhadap literatur agar dapat memformulasikan beberapa hipotesa. Hipotesa diuji melalui uji statistik - uji inferensial. Struktural Equation Model teknik dipilih untuk digunakan dalam menganalisa data. Teknik ini merupakan teknik analisa yang dapat menguji model konseptual dengan kompleksitas yang relatif.

Terdapat tiga evaluasi langkah yang akan dilakukan dalam menggunkan teknik SEM. Pertama, melakukan analisa terhadap pengukuran yang digunakan. Evaluasi yang dilakukan adalah dengan mengevaluasi validitas diskriminan, validitas konvergen dan uni 


\section{Sumiati}

dimensionalitas dari keseluruhan konstruk. Kedua, melakukan analisis dan evaluasi terhadap model struktural yang dirancang dengan melihat nilai koefisien determinasi total dan goodness of fitmodel. Ketiga, pengujian hipotesa baik pengaruh langsung maupun pengaruh tidak langsung. Pengaruh tidak langsung diuji dengan menggunakan sobel test. Menurut Hair et al. (2014) pengujian hipotesa, alpha ditentukan pada level 5\% dengan $t=$ $1,960$.

\section{HASIL DAN DISKUSI}

\section{Karakteristik Responden}

Mayoritas responden dalam penelitian ini adalah laki-laki (59\%). Sebanyak 67 orang responden berusia antara 46 hngga 55 tahun, dan sebagian besar responden berpendidikan setara diplom (47\%). Sebanyak 79 responden $(42 \%)$ mengaku telah menjalankan bisnisnya selama 3 hingga 5 tahun. Adapun karakteristik responden dalam penelitian ini secara lengkap tersaji dalam Tabel 1.

\section{Tabel 1.}

Karakteristik Responden

\begin{tabular}{llcc}
\hline \multicolumn{1}{c}{ Variabel } & \multicolumn{1}{c}{ Klasifikasi } & Jumlah & \% \\
\hline Jenis Kelamin & Laki-laki & 110 & $59 \%$ \\
Umur & Perempuan & 76 & $41 \%$ \\
& 18-25 tahun & 12 & $6 \%$ \\
& $26-35$ tahun & 23 & $12 \%$ \\
& 36-45 tahun & 48 & $26 \%$ \\
& $46-55$ tahun & 67 & $36 \%$ \\
Pendidikan & >55 tahun & 36 & $19 \%$ \\
& SMA & 58 & $31 \%$ \\
& Diploma & 88 & $47 \%$ \\
& S1 & 19 & $10 \%$ \\
& S2 & 21 & $11 \%$ \\
Lama berbisnis & S3 & 0 & $0 \%$ \\
& 6-5 tahun & 79 & $42 \%$ \\
& 6-10 tahun & 45 & $24 \%$ \\
& tahun & 27 & $15 \%$ \\
& $>15$ tahun & 34 & $18 \%$ \\
& Tidak menjawab & 2 & $1 \%$ \\
\hline
\end{tabular}

\section{Evaluasi Model: Hasil Model Pengukuran}

Model pengukuran (measurement model) merupakan elemen dari model jalur yang mencakup indikator dan hubungannya antar konstruk, ini disebut model luar dalam PLS-SEM. Model pengukuran mencakup korelasi antar-konstruk (reliabilitas alpha dan komposit Cronbach) untuk mengevaluasi konsistensi internal dan varians rata-rata yang diekstrak atau yang diketahui dengan AVE (average variance extracted)untuk mengevaluasi validitas konvergen (Fornell, 1982). Tabel 3 menyajikan reliabilitas, validitas, dan matriks korelasi. Bagian dari measurement model terdiri dari: (1). Individual loading dari setiap item 


\section{Jurnal Manajemen Teori dan Terapan \\ Tahun 12. No. 3, Desember 2019}

pertanyaan. (2). Internal Composite Reliability (ICR). (3). Average Variance Extracted (AVE), dan (4). Discriminant Validity.

Composite Reliability (CR) lebih baik dalam mengukur internal consistency dibandingkan Cronbach's Alpha dalam SEM karena CR tidak mengasumsikan kesamaan boot dari setiap indikator. Cronbach's Alpha cenderung menaksir lebih rendah construct reliability dibandingkan Composite Reliability (CR).

Interpretasi Composite Reliability (CR) sama dengan Cronbach's Alpha. Nilai batas $>0.7$ dapat diterima, dan nilai > 0.8 sangat memuaskan. Hasil penelitian ini menunjukkan dari keempat variabel yang ada, hanya tiga variable saja (Inovasi sebesar 0,833; Orientasi Pasar sebesar 0,812; dan Fleksibilitas Strategi sebesar 0,720) yang memiliki kategori Cronbach alfa bagus. Untuk kinerja perusahaan memiliki Cronbach alpha sebesar 0,533 yang mana ini termasuk dalam kategori validitas convergen yang rendah. Ukuran keandalan yang berbeda atau disebut composite reliability, tidak mengasumsikan pembebanan indikator yang sama. Menurut Nunnally dan Bernstein (1994), composite reliability yang lebih besar dari 0,70 dapat dianggap memuaskan. Composite reliability dari keempat variabel berkisar dari 0,770 hingga 0,822 , menunjukkan reliabilitas yang baik.

Penilaian model pengukuran reflektif juga mencakup convergent validity, sejauh mana suatu ukuran berkorelasi positif dengan langkah-langkah alternatif dari konstruk yang sama. Mengikuti Hair et al. (2014), pengukuran convergent validity bisa kita lihat melalui hasil Average Variance Extracted (AVE) dan hasil outer loading. AVE digunakan untuk mengukur banyaknya varians yang dapat ditangkap oleh konstruknya dibandingkan dengan variansi yang ditimbulkan oleh kesalahan pengukuran, dan harus lebih besar dari 0,5 sehingga $50 \%$ atau lebih dari varian indikator dapat dipertanggungjawabkan. Keseluruhan variabel dalam penelitian ini memenuhi kriteria berkisar dari 0,543 hingga 0,667 , hal ini menunjukkan validitas konvergen yang baik.

Pengukuran discriminant validity merupakan sejauh mana konstruk yang diberikan berbeda dari konstruksi lain. Ada dua pendekatan klasik dalam mengukur discriminant validity. Pendekatan pertama berdasarkan Fornell (1982) dengan membandingkan akar kuadrat AVE dengan korelasi antara konstruk, di mana elemen diagonal (ditampilkan pada Tabel 3) harus lebih besar daripada koefisien korelasi antara konstruk dan konstruk lainnya dalam model. (off diagonal). Hasil yang ditunjukkan pada Tabel 3 menunjukkan discriminant validity yang baik. 


\section{Sumiati}

Tabel 2.

Inter-Construct Correlations (Reliability, Validity, and Correlation Matrix)

\begin{tabular}{llllllll}
\hline \multirow{2}{*}{ Construct } & \multicolumn{2}{c}{ Reliability } & \multicolumn{3}{c}{$\begin{array}{c}\text { Convergent } \\
\text { Validity }\end{array}$} & \multicolumn{3}{c}{ Correlation and Discriminant Validity } \\
\cline { 2 - 8 } & $\begin{array}{l}\text { Composite } \\
\text { Reliability }\end{array}$ & $\begin{array}{c}\text { Cronbach } \\
\text { Alpha }\end{array}$ & AVE & $\begin{array}{l}\text { External } \\
\text { Environ } \\
\text { ment }\end{array}$ & $\begin{array}{l}\text { Internal } \\
\text { Environ } \\
\text { ment }\end{array}$ & $\begin{array}{l}\text { Market } \\
\text { Orientation }\end{array}$ & $\begin{array}{l}\text { Strategic } \\
\text { Flexibility }\end{array}$ \\
\hline $\begin{array}{l}\text { Inovasi } \\
\text { Orientasi }\end{array}$ & 0,889 & 0,833 & 0,667 & 0,817 & & & \\
$\begin{array}{l}\text { Pasar } \\
\text { Kinerja }\end{array}$ & 0,869 & 0,812 & 0,573 & 0,601 & 0,757 & & \\
$\begin{array}{l}\text { Perusahaan } \\
\text { Fleksibilitas }\end{array}$ & 0,770 & 0,853 & 0,555 & 0,492 & 0,357 & 0,745 & \\
\hline
\end{tabular}

Pendekatan kedua adalah milik Barclay et al. (1995) yang menggunakan cross loadings. Nilai cross loading ini merupakan ukuran lain dari validitas diskrimanan. Nilai yang diharapkan bahwa setiap indikator memiliki loading lebih tinggi untuk konstruk yang diukur dibandingkan dengan nilai cross loading ke konstruk yang lain. Kriteria ini umumnya dianggap agak liberal dalam hal menetapkan discriminant validity (Hair et al., 2014). Sebagaimana Hulland (1999) mengemukakan bahwa outer loadings yang lebih lemah sering diamati dalam studi ilmu sosial. Menurut Hair et al. (2014) harus berhati-hati dalam menghilangkan indikator dengan outer loadings di bawah 0,70.

Umumnya, indikator dengan outer loadings lebih rendah dari 0,70 harus dipertimbangkan penghapusan hanya saja ketika menghapus indikator mengarah pada peningkatan varians rata-rata yang ditambahkan atau dengan composite reliability di atas batas nilai yang disarankan. Tabel 2 menyajikan hasil outer loadings dan cross loadings yang memenuhi kriteria.

Pada evaluasi model struktural, determinant coefficient $\left(R^{2}\right)$, predictive relevance $\left(Q^{2}\right)$ dan ukuran relatif dari efek path analysis ( $f^{2}$ dan $q^{2}$ ) digunakan. Dengan menginterpretasikan hasil ini, peneliti dapat mengidentifikasi model konstruk dengan relevansi tinggi untuk menjelaskan variabel laten endogen dalam model struktural. Model struktural dalam penelitian ini adalah model rekursif, artinya hanya satu arah kausalitas yang diperbolehkan, dan tidak mengandung arah umpan balik pada konstruk (Chin, 2010). Tabel 3 menyajikan hasil dari $\mathrm{R}^{2}$ dan $\mathrm{Q}^{2}$ dari konstruk

Berdasarkan Hair et al. (2014), determinant coefficient $\left(R^{2}\right)$ nilai $0,75,0,50$, dan 0,25 digambarkan sebagai aturan untuk kriteria kuat, sedang, dan lemah. Variabel inovasi memiliki nilai $\mathrm{R}^{2}$ paling besar yaitu 0,453 ini bisa dikatakan masuk dalam kriteria cukup sedang. Sedangkan untuk variable kinerja perusahaan memiliki nilai terkecil sebesar 0,295 hal ini menunjukkan bahwa kedua variabel endogen memiliki varian konstruk yang lemah. 
Tabel 3 memberikan ukuran efek ( $f^{2}$ ) dari variabel eksogen ke variabel endogen. Kriteria nilai $f^{2}$ adalah $0,02,0,15$, dan 0,35 untuk mewakili efek kecil, sedang, dan besar dari variabel laten eksogen (Hair et al., 2014).

Tabel 3.

Outer Loadings and Cross Loadings

\begin{tabular}{|c|c|c|c|c|c|}
\hline & INO & MO & Perf & SF & \\
\hline INO1.1 & 0,803 & & & & \\
\hline INO1.2 & 0,825 & & & & \\
\hline INOI.3 & 0,853 & & & & \\
\hline INOI.4 & 0,785 & & & & \\
\hline $\mathrm{MOl}$ & & 0,636 & & & Dihapus \\
\hline $\mathrm{MO} 2$ & & 0,772 & & & \\
\hline MO3 & & 0,861 & & & \\
\hline MO4 & & 0,745 & & & \\
\hline MO5 & & 0,754 & & & \\
\hline PER 1.2 & & & 0,364 & & Dihapus \\
\hline PER2.1 & & & 0,888 & & \\
\hline PER2.2 & & & 0,862 & & \\
\hline SF3 & & & & 0,652 & Dihapus \\
\hline SF4 & & & & 0,573 & Dihapus \\
\hline SF5 & & & & 0,846 & \\
\hline SF6 & & & & 0,838 & \\
\hline
\end{tabular}

Evaluasi Model: Hasil Model Struktural

Tabel 4.

Evaluasi Model Structural melalui determinant coefficient $\left(\mathrm{R}^{2}\right)$

\begin{tabular}{lll}
\hline & R Square & R Square Adjusted \\
\hline Inovasi & 0,453 & 0,447 \\
Kinerja perusahaan & 0,295 & 0,284 \\
\hline
\end{tabular}

Tabel 5.

Efek Hubungan $\mathrm{f}^{2}$

\begin{tabular}{lll}
\hline & Endogenous & Mediator \\
\hline Variable & Kinerja Perusahaan & Inovasi \\
& $\mathrm{f} 2$ & \\
Exogenous 1: Fleksibilitas Strategi & 0,067 & 0,186 \\
Exogenous 2: Orientasi Pasar & 0,002 & 0,309 \\
Mediator: Inovasi & 0,081 & \\
\hline
\end{tabular}

Ukuran dampak $f 2$ menunjukkan apakah variabel laten endogen memiliki pengaruh besar terhadap variabel laten eksogen dengan dihitung sebagai berikut:

$$
f^{2}=\frac{R^{2} \text { include }-R^{2} \text { exclude }}{1-R^{2} \text { include }}
$$




\section{Sumiati}

Berdasarkan kriteria yang ada untuk $f 2$, variabel eksogen fleksibilitas strategi dan orientasi pasar serta variabel mediator inovasi memiliki effect size rendah terhadap variabel endogen kinerja perusahaan $(0,067 ; 0,002 ; 0,081)$. Pengaruh variabel eksogen fleksibilitas strategi terhadap inovasi sebagai mediator memiliki effect size sedang $(0,186)$. Sedangkan pengaruh variabel eksogen orientasi pasar terhadap inovasi sebagai mediator adalah sedang cenderung tinggi $(0,309)$.

\section{Pengujian Hipotesis}

Setelah menjelaskan item pengukuran, langkah selanjutnya adalah menguji hubungan antar variabel. PLS dapat menghasilkan p-value untuk pengujian signifikansi hipotesis dari model, menggunakan prosedur yang disebut bootstrapping.

\section{Table 6.}

Hypotheses Testing

\begin{tabular}{|c|c|c|c|c|}
\hline \multirow[b]{2}{*}{ Hypothesis } & \multicolumn{2}{|c|}{ Direct and Indirect } & \multicolumn{2}{|c|}{ Total Effect } \\
\hline & $\begin{array}{c}\text { Path } \\
\text { Coefficients }\end{array}$ & Support & $\begin{array}{c}\text { Path } \\
\text { Coefficients }\end{array}$ & Support \\
\hline $\begin{array}{l}\text { Direct Effects } \\
\text { H1: Fleksibilitas Strategi } \rightarrow \text { Kinerja } \\
\text { Perusahaan }\end{array}$ & 0,260 & diterima & 0,369 & diterima \\
\hline $\begin{array}{l}\text { H2: Orientasi Pasar } \rightarrow \text { Kinerja } \\
\text { Perusahaan }\end{array}$ & 0,050 & diterima & 0,197 & diterima \\
\hline H3: Fleksibilitas Strategi $\rightarrow$ Inovasi & 0,336 & diterima & 0,336 & diterima \\
\hline H4: Orientasi Pasar $\rightarrow$ Inovasi & 0,456 & diterima & 0.456 & diterima \\
\hline $\begin{array}{l}\text { H5: Inovasi } \rightarrow \text { Kinerja Perusahaan } \\
\text { Indirect Effects }\end{array}$ & 0,323 & diterima & 0,323 & diterima \\
\hline $\begin{array}{l}\text { H6: } \quad \text { Fleksibilitas } \\
\text { Strategi } \rightarrow \text { Inovasi } \rightarrow \text { Kinerja } \\
\text { Perusahaan }\end{array}$ & 0,109 & diterima & & \\
\hline $\begin{array}{l}\text { H7: } \\
\text { Pasar } \rightarrow \text { Inovasi } \rightarrow \text { Kinerja } \\
\text { Perusahaan }\end{array}$ & 0,147 & diterima & & \\
\hline
\end{tabular}

Significant: ${ }^{* *} p$-value $>0,05$

Bedasarakan hasil pengujian hipotesis diketahui bahwa kinerja perusahaan akan meningkat seiring adanya peningkatan fleksibilitas strategi dan orientasi pasar. Semakin fleksibel strategi yang ditetapkan oleh perusahaan akan mendorong semakin tingginaya kinerja perusahaan. Hal ini didukung oleh penelitian yang dilakukan oleh Zhang (2005) and Nadkarni dan Herrmann (2010). Ketika sebuah perusahaan ingin meningkatkan kinerja nya baik secara finansial maupn non finansial, maka manajer harus memperhatikan fleksibilitas strategi yang diterapkan. Perusahaan dengan flexibility strategy yang tinggi akan dengan meudah membagi sumberdaya dalam setiap unitnya. Lebih lanjut, perusahaan dengan strategic flexibility yang tinggi akan selalu mengevaluasi dan meninjau rencana strategisnya untuk disesuaikan dengan kondisi yang ada. Dengan demikian, semakin fleksibel strategi 


\section{Jurnal Manajemen Teori dan Terapan \\ Tahun 12. No. 3, Desember 2019}

yang diterapkan dalam suatu perusahaan akan semakin menigkatkan performce dari perusahaan tersebut.

Lebih lanjut, sebuah perusahaan dengan orientasi pasar yang tinggi juga akan menghasilkan performance yang tinggi. Semakin perusahaan memahami kemauan konsumen maka perusahaan akan menyediakan barang dan jasa yang sesuai. Dengan demikian performance perusahaan akan menigkat baik secara finansial maupun non finansial. Hal ini didukung oleh penelitian yang dilakukan oleh penelitian terdahulu dalam berbagai industri (Gruber-Muecke dan Hofer, 2015; Morgan et al., 2009; Wang et al., 2012; Zhou et al., 2009).

Kinerja perusahaan juga terbukti akan meningkat secara signifikan dengan adanya inovasi yang dilakukan oleh perusahaan. Inovasi yang perlu dilakukan oleh perusahaan terdiri atas dua jenis invasi yaitu eksploratif dan eksploitatif inovasi. Dalam hal eksploratif inovasi, perusahaan seharusnya megeksplor berbagai kegiatan inovasi yang belum pernah dilakukan oleh perusahaan. Sedangkan dalam hal eksploitatif inovasi, perusahaan seharusnya selalu melakukan perbaikan melaui tindakan-tindakan inovasi terhadap bisnis prose maupun produk/jasa yang telah dihasilkan/dilakukan. Dengan demikian inovasi yang dilakukan akan meningkatkan performance perusahaan. Penelitian ini didukung oleh Naranjo-Valencia et al. (2016) dan Hogan dan Coote (2014) yang menemukan bahwa inovasi akan meningkatkan kinerja perusahaan.

Lebih lanjut, penelitian ini juga menemukan bahwa inovasi perusahaan akan meningkat seiring dengan peningkatan orientas pasar yang dilakukan perusahaan. Semakin tinggi orientasi perusahaan terhadap pasar sasaran, maka akan meningkatkan persepektif perusahaan terhadapt inovasi yang dapat dilakukan. Seiring dengan berkembangnya keinginan pasar, perusahaan yang memiliki orientasi tinggi terhadap pasar juga akan memiliki orientasi inovasi yang tinggi pula. Hal ini didukung oleh penelitian terdahulu yang juga menemukan bahwa orientasi pasar berpengaruh positif dan signifikan terhadap inovasi (Al Idrus et al., 2019; Laforet, 2008; Nasution et al. 2011).

\section{SIMPULAN}

Penelitian ini bertujuan untuk menguji pengaruh orientasi pasar dan fleksibilitas strategi terhadap inovasi dan kinerja UKM menjadikan penelitian ini sebagai penelitian eksplanatori. Dengan menggunakan sampel sebanyak 200 responden yang berprofesi sebagai manajer UKM industri pengolahan di Kota Malang. Fleksibilitas strategi dan orientasi pasar ditemukan secara langsung (direct effect) mempengaruhi inovasi dan kinerja perusahaan secara positif. Selain itu, inovasi teruji berperan sebagai mediator dalam pengaruh fleksibilitas 


\section{Sumiati}

strategi maupun orientasi pasar terhadap kinerja perusahaan. Begitu pula dengan kinerja perusahaan teruji berperan sebagai mediator bagi masing-masing fleksibilitas strategi maupun orientasi pasar terhadap inovasi. Hasil uji hipotesis menunjukkan bahwa fleksibilitas strategi dan orientasi pasar memiliki peran yang signifikan dalam peningkatan inovasi dan kinerja perusahaan pada Industri Pengolahan UMKM di Kota Malang.

Penelitian ini diharapkan memberikan kontribusi secara teoritis mengenai pengaruh fleksibilitas strategi dan orientasi pasar terhadap inovasi dan kinerja perusahaan kecil dan menengah. Lebih lanjut, secara praktis penelitian ini diharapkan dapat membantu para manajer dan pemilik UKM untuk dapat mengalokasikan sumberdayanya secara efektif untuk meningkatkan kinerja perusahannya.

Penelitian ini selain memberikan kontribusi secara oraktis dan teoritis, juga tentunya memiliki keterbatasan. Karena penelitian ini hanya mengambil sampel pengusaha kecil dan menengah di Kota Malang, maka hasil penelitian ini tidak dapat digeneralisasi dengan mudah. Hasil penelitian ini bisa jadi berbeda apabila diterapkan pada konteks dan setting penelitian dengan karakteristik responden dan budaya yang berbeda. Oleh karena itu, penelitian selanjutnya diharapkan mampu mereplikasi penelitian ini pada objek dan setting yang berbeda. Lebih lanjut, penelitian selanjutnya juga diharapkan dapat mengembangkan penelitian ini dengan mengintegrasi konstruk yang baru dan juga objek penelitian yang belum diuji secara luas seperti keterbukaan finansial, intensitas wairausaha dan konstruk lain guna memperkaya wawasan empiris dalam peningkatan kinerja perusahaan dan inovasi UMKM.

\section{DAFTAR PUSTAKA}

Idrus, A. S., Ahmar, A. S., dan Abdussakir, A. 2019. The influence of business innovation with relationship of organizational learning and job satisfaction on market orientation. Journal of Science and Technology Policy Management.

Aziz, N. N. A., dan Samad, S. 2016. Innovation and competitive advantage: Moderating effects of firm age in foods manufacturing SMEs in Malaysia. Procedia Economics and Finance. 35: 256-266.

Barclay, D., Higgins, C., dan Thompson, R. 1995. The partial least squares (PLS) approach to casual modeling: personal computer adoption ans use as an Illustration.

Brozovic, D. 2018. Strategic flexibility: A review of the literature. International Journal of Management Reviews. 20(1):3-31.

Chan, A. T., Ngai, E. W., dan Moon, K. K. 2017. The effects of strategic and manufacturing flexibilities and supply chain agility on firm performance in the fashion industry. European Journal of Operational Research. 259(2): 486-499. 


\section{Jurnal Manajemen Teori dan Terapan \\ Tahun 12. No. 3, Desember 2019}

Chin, W. W. (2010). How to write up and report PLS analyses Handbook of partial least squares: 655-690. Springer.

Doluca, H., Wagner, M., dan Block, J. 2018. Sustainability and environmental behaviour in family firms: A longitudinal analysis of environment-related activities, innovation and performance. Business Strategy and the Environment. 27(1): 152-172.

Drucker, P. 2014. Innovation and entrepreneurship: Routledge.

Hair, F. J. J., Sarstedt, M., Hopkins, L., dan Kuppelwieser, G. V. 2014. Partial least squares structural equation modeling (PLS-SEM) An emerging tool in business research. European Business Review. 26(2): 106-121.

Fairoz, F. M., Hirobumi, T., dan Tanaka, Y. 2010. Entrepreneurial orientation and business performance of small and medium scale enterprises of Hambantota District Sri Lanka. Asian Social Science. 6(3): 34.

Fornell, C. 1982. A second generation of multivariate analysis. 2. Measurement and evaluation. 2. Praeger Publishers.

Gomes, G., dan Wojahn, R. M. 2017. Organizational learning capability, innovation and performance: study in small and medium-sized enterprises (SMES). Revista de Administração (São Paulo). 52(2): 163-175.

Grewal, R., dan Tansuhaj, R. 2001. Building Organizational Capabilities for Managing Economic Crisis: The Role of Market Orientation and Strategic Flexibility. Journal of Marketing. 65(2). DOI: https://doi.org/10.1509/jmkg.65.2.67.18259

Gruber-Muecke, T., dan Hofer, K. M. 2015. Market orientation, entrepreneurial orientation and performance in emerging markets. International Journal of Emerging Markets. 10(3): 560-571.

Higgins, J. M. 1995. Innovation: The core competence. Planning review. 23(6): 32-36.

Hogan, S. J., dan Coote, L. V. 2014. Organizational culture, innovation, and performance: A test of Schein's model. Journal of Business Research. 67(8): 1609-1621.

Hulland, J. 1999. Use of partial least squares (PLS) in strategic management research: A review of four recent studies. Strategic Management Journal. 20(2): 195-204.

Laforet, S. 2008. Size, strategic, and market orientation affects on innovation. Journal of Business Research. 61 (7): 753-764.

Mele, C., dan Russo-Spena, T. 2015. Innomediary agency and practices in shaping market innovation. Industrial Marketing Management. 44: 42-53.

Migdadi, M. M., Zaid, M. K. A., Yousif, M., Almestarihi, R. d., dan Al-Hyari, K. 2017. An empirical examination of knowledge management processes and market orientation, innovation capability, and organisational performance: Insights from Jordan. Journal of Information \& Knowledge Management. 16(01): 1750002.

Morgan, N. A., Vorhies, D. W., dan Mason, C. H. 2009. Market orientation, marketing capabilities, and firm performance. Strategic Management Journal. 30(8): 909-920. 


\section{Sumiati}

Murat Ar, I., dan Baki, B. 2011. Antecedents and performance impacts of product versus process innovation: Empirical evidence from SMEs located in Turkish science and technology parks. European Journal of Innovation Management. 14(2): 172-206.

Nadkarni, S., dan Herrmann, P. 2010. CEO personality, strategic flexibility, and firm performance: The case of the Indian business process outsourcing industry. Academy of Management Journal. 53(5): 1050-1073.

Naranjo-Valencia, J. C., Jiménez-Jiménez, D., dan Sanz-Valle, R. 2016. Studying the links between organizational culture, innovation, and performance in Spanish companies. Revista Latinoamericana de Psicología. 48(1): 30-41.

Nasution, H. N., Mavondo, F. T., Matanda, M. J., dan Ndubisi, N. O. 2011 . Entrepreneurship: Its relationship with market orientation and learning orientation and as antecedents to innovation and customer value. Industrial Marketing Management. 40(3): 336-345.

Nenonen, S., Möller, K., dan Storbacka, K. (2017). Market innovation: renewal of traditional industrial networks Innovating in Practice: 59-81. Springer.

Nunnally, J. C., dan Bernstein, I. H. 1994. Psychological theory. New York: McGraw-Hill.

Ozkaya, H. E., Droge, C., Hult, G. T. M., Calantone, R., dan Ozkaya, E. 2015. Market orientation, knowledge competence, and innovation. International Journal of Research in Marketing. 32(3): 309-318.

Semrau, T., Ambos, T., dan Kraus, S. 2016. Entrepreneurial orientation and SME performance across societal cultures: An international study. Journal of Business Research. 69(5): 1928-1932.

Wang, C.-H., Chen, K.-Y., dan Chen, S.-C. 2012. Total quality management, market orientation and hotel performance: The moderating effects of external environmental factors. International Journal of Hospitality Management. 31 (1): 119-129.

Zhang, J., dan Duan, Y. 2010. The impact of different types of market orientation on product innovation performance: Evidence from Chinese manufacturers. Management Decision. 48(6): 849-867.

Zhang, M. J. 2005. Information systems, strategic flexibility and firm performance: an empirical investigation. Journal of Engineering and Technology Management. 22 (3): 163-184.

Zhou, K. Z., Brown, J. R., dan Dev, C. S. 2009. Market orientation, competitive advantage, and performance: A demand-based perspective. Journal of Business Research. 62(11): 1063-1070. 